\title{
Does Coordination of Immigration Policies among Destination Countries Increase Immigration?
}

\author{
Rose Skaksen, Jan; Malchow-Møller, Nikolaj; Aastrup Jensen, Claus
}

Document Version

Final published version

Publication date:

2007

License

CC BY-NC-ND

Citation for published version (APA):

Rose Skaksen, J., Malchow-Møller, N., \& Aastrup Jensen, C. (2007). Does Coordination of Immigration Policies among Destination Countries Increase Immigration? Centre for Economic and Business Research, Copenhagen Business School.

Link to publication in CBS Research Portal

\footnotetext{
General rights

Copyright and moral rights for the publications made accessible in the public portal are retained by the authors and/or other copyright owners and it is a condition of accessing publications that users recognise and abide by the legal requirements associated with these rights.

Take down policy

If you believe that this document breaches copyright please contact us (research.lib@cbs.dk) providing details, and we will remove access to the work immediately and investigate your claim.
}

Download date: 26. Apr. 2023 


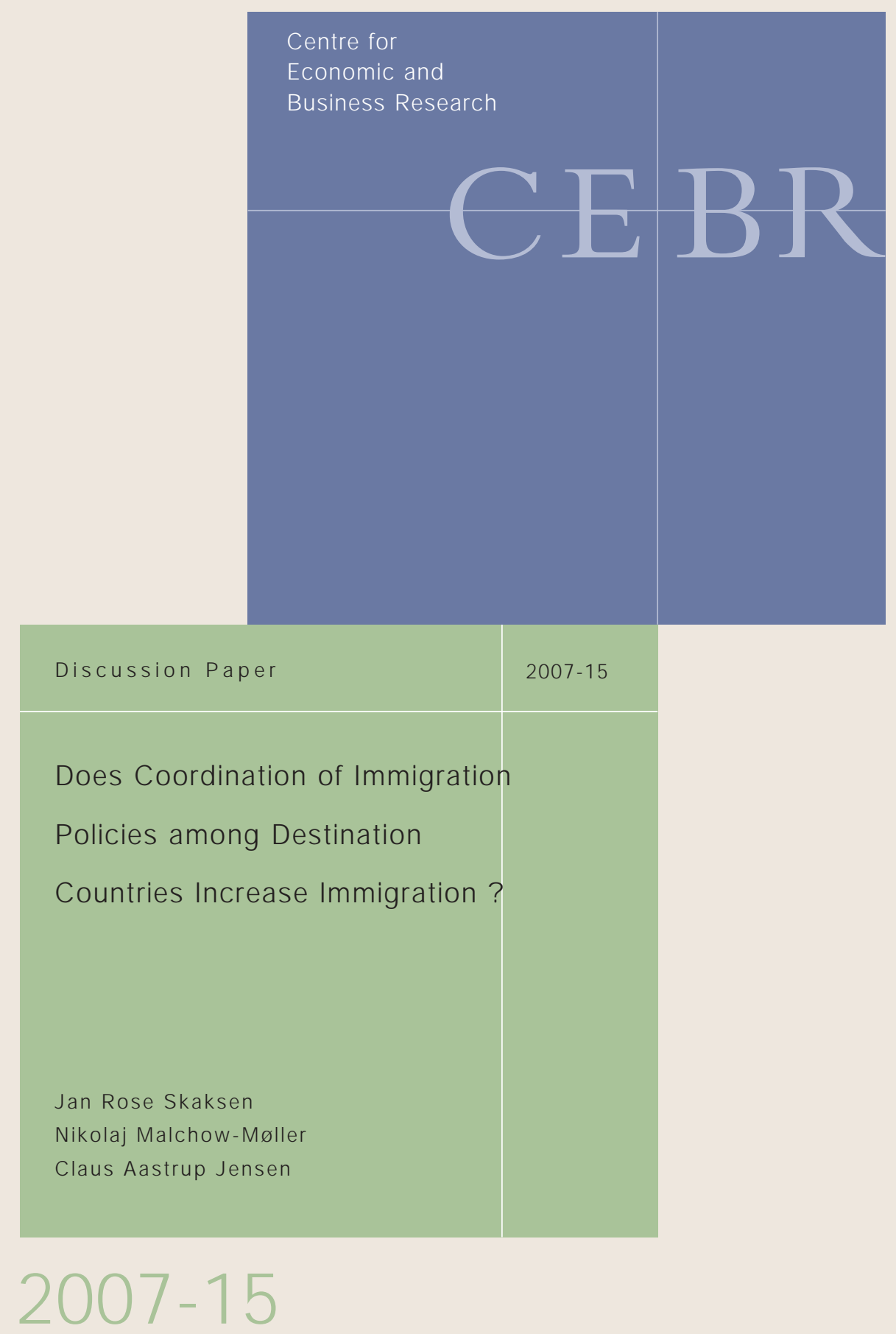




\title{
Does Coordination of Immigration Policies among Destination Countries Increase Immigration?*
}

\author{
Claus Aastrup Jensen \\ University of Southern Denmark, \\ CEBR
}

\author{
Nikolaj Malchow-Møller \\ CEBR \\ University of Southern Denmark,
}

\author{
Jan Rose Skaksen \\ Copenhagen Business School, \\ CEBR and IZA
}

July 2, 2007

\begin{abstract}
We set up a theoretical model to analyze the implications of coordination of immigration policies among destination countries. The model contains two types of spill-overs between destination countries: A terms of trade externality and a welfare policy externality. We show that while coordination unambiguously increases welfare of the destination countries, the effects on the level of immigration and on the income distribution of natives are ambiguous. Thus, coordination among destination countries does not necessarily solve the global coordination problem of inoptimally low levels of migration.
\end{abstract}

Keywords: Coordination, Externalities, Immigration Policy, Spill-overs, Terms of Trade, Welfare.

JEL Classification: F22, F42.

\footnotetext{
*This paper is part of a joint project between CEBR and the Rockwool Foundation Research Unit. Financial support from the Rockwool Foundation is gratefully acknowledged.
} 


\section{Introduction}

The potential world wide gains from liberalizing migration flows are enormous and have been increasing in recent decades; see, e.g., Moses and Letnes (2004). ${ }^{1}$ Despite this increase, the tendency in policies has been to restrict immigration; see, e.g., Boeri and Brücker (2005) and Hatton (2007). This apparent paradox seems to call for coordination of migration policies.

Reaping the full gains from migration requires coordination of migration policies among the grand coalition of both source and destination countries, but as argued in Hatton (2007) such coordination may be very difficult to implement because the gains from migration mainly accrue to the migrants themselves. However, there may also be a case for coordination between destination countries alone, where particularly two types of spill-overs - a terms-of trade externality and a welfare policy externality - may give rise to coordination failures across national jurisdictions; see also Boeri and Brücker (2005). Furthermore, coordination among destination countries is also the most likely policy scenario in the case of, e.g., the European Union where such policy measures are currently discussed; see, e.g., European Commission (2005).

The question is whether such (partial) coordination among destination countries will give rise to more immigration and thus help solve the overall coordination problem between source and destination countries? And how does it affect the welfare and income distribution of the destination countries?

To answer these questions, we set up a theoretical model where immigrants are heterogenous with respect to their performance at the labor market. There are a number of host countries which are able to choose their levels of immigration but not the specific types of immigrants as this is private information of the immigrants. However, a country can attract certain types of immigrants by offering different combinations of taxes, wages and social benefits.

\footnotetext{
${ }^{1}$ Moses and Letnes (2004) analyse different scenarios, but in a middle scenario they find that in 1977 , the gain from introducing free migration would be $7.5 \%$ of world GDP. In 1998, this number has increased to $9.6 \%$.
} 
In our model, there are two types of spill-over effects of immigration policy between the destination countries. First, there is a terms of trade effect. Immigration increases host country production, and causes wages and prices to decrease in this country, which in turn, gives rise to cheaper imports for other countries. This terms of trade externality is a standard feature in analyses of fiscal policy coordination; see, e.g., Chari and Kehoe (1990), Devereux (1991), Devereux and Mansoorian (1992), Dixon and Santoni (1997), and Beetsma and Uhlig (1999). We show that this effect is also in play when considering immigration policy.

Second, destination countries can use fiscal policy to attract immigrants with high employment rates, who will contribute to the financing of the welfare state. As this will also affect the composition of the immigrants flowing to other destination countries, it creates a welfare policy externality. This type of externality is known from the literature on fiscal competition among local governments; see, e.g., Wildasin (1991, 1994).

While coordination of immigration policies among destination countries always raises the welfare of the destination countries, we find that it is ambiguous whether it gives rise to more or less immigration than in the case of uncoordinated policies. Specifically, we find that if the terms of trade externality of immigration dominates the welfare policy externality, coordination gives rise to more immigration. On the other hand, if the dominating externality associated with immigration is the welfare policy externality, then coordination of immigration policies actually reduces immigration.

Besides considering how coordination affects the level of immigration, we also analyze how coordination affects the distribution of income in the destination countries. Again, the results are in general ambiguous, but if immigrants have relatively low employment rates and/or the terms of trade externality is the most important, people outside the labor force will lose on coordination relatively to people in the labor force.

The implications for immigration and welfare of coordinating policies among a group of destination countries have so far only received very limited attention in the literature. One study is Hansen (2003) where the focus is on how immigration may affect welfare policies. He considers a political economy model where median voters in the destination 
countries may be affected by the fiscal burden of welfare payments to immigrants. By comparing uncoordinated, coordinated and leader-follower determined welfare policies, it is shown that median voters (or populations in general) in rich countries will benefit from coordination of welfare benefits, and that a position as a follower country is preferred by the median voter to a position as a leader country, because of a less generous welfare system and hence fewer immigrants. In the paper by Hansen (2003), the focus is on how the coordination of welfare policies affect immigration, whereas our focus is on coordination of the immigration policies.

The issue of location choices made by immigrants is analyzed by, e.g., Borjas (1999) who shows that interstate dispersion in welfare benefits in the US affects the geographical clustering of low-skilled immigrants with immigrant welfare recipients more heavily concentrated in states offering high benefits.

The rest of the paper is structured as follows. In Section 2, we set up the model. The model is solved and results are presented in Section 3. Section 4 concludes. Technical details and proofs of propositions are relegated to an appendix.

\section{The Model}

In this section we set up the model. In Subsection 2.1, we describe the basic macroeconomic model, which is a model of $n$ symmetric destination countries each producing a separate good which is traded among them. Two types of natives are present in the economies - those in the labor force and those outside the labor force. The government seeks to maximize a utilitarian welfare function defined over natives by deciding on immigration and welfare policies (taxes and benefits) under the restriction of a balanced public budget.

In Subsection 2.2, we describe the behavior of immigrants in response to the welfare policies of the destination countries. We assume that destination countries can control the number but not the type of immigrants - at least not perfectly. In Subsection 2.3, we describe the resulting policy game between destination countries, in both the uncoor- 
dinated and the coordinated case, when they have to decide on optimal immigration and welfare policies.

\subsection{The Basic Model}

We assume that there are $n$ similar countries each producing one good which is an imperfect substitute in consumption for the $n-1$ goods produced in the other countries.

The utility function of individual $h$ in country $i$ is given as:

$$
U_{h i}=\ln \left(C_{h i}\right)+\gamma_{0} N_{i}^{I}-\gamma_{1}\left(N_{i}^{I}\right)^{2}, \quad \gamma_{0}>0, \quad \gamma_{1}>0
$$

where $C_{h i}$ is a consumption index over the $n$ goods. Note that the number of immigrants, $N_{i}^{I}$, in country $i$ enters the utility function directly through the last two terms to capture preferences for immigration not accounted for by the effects on consumption possibilities. This could be factors like cultural diversity, social/global responsibility, racism, etc.; see, e.g., Dustman and Preston (2004), Hillman (2002) or Hansen (2003). We assume that $\gamma_{0}>0$ and $\gamma_{1}>0$ meaning that this direct utility effect of immigration is initially positive, but eventually turns negative, as the marginal utility of immigrants is assumed to be decreasing. ${ }^{2}$

The consumption index, $C_{h i}$, is a CES function of the consumption of the $n$ goods produced by the $n$ countries: ${ }^{3}$

$$
C_{h i}=n^{\frac{1}{1-\theta}}\left(\sum_{j=1}^{n} c_{h i j}^{\frac{\theta-1}{\theta}}\right)^{\frac{\theta}{\theta-1}}
$$

We assume that $\theta>1$, i.e. the degree of substitutability between the goods is sufficiently high that no goods are essential in consumption.

Maximizing utility subject to an individual budget constraint, the demand for good $j$

\footnotetext{
${ }^{2}$ As we shall see, the specification of this part of the utility function is not crucial for the results, but its presence can ensure the existence of interior solutions to the policy game described in Section 2.3.

${ }^{3}$ For simplicity, and without any implications for our results, the coefficient, $n^{\frac{1}{1-\theta}}$, is included in order to avoid a "love of variety" effect, which would complicate the analytics.
} 
of individual $h$ in country $i$ is given by:

$$
c_{h i j}=\left(\frac{P_{j}}{P}\right)^{-\theta} \frac{1}{n}\left(\frac{z_{h i}}{P}\right)
$$

where $P_{j}$ is the price of good $j, z_{h i}$ is the after tax income of individual $h$ in country $i$, and $P$ is a price index defined by:

$$
P=\left(\frac{1}{n} \sum_{j=1}^{n} P_{j}^{1-\theta}\right)^{\frac{1}{1-\theta}}
$$

which we in the following normalize to one, $P=1$. The price elasticity of demand is $-\theta$.

For simplicity, we assume that there is no disutility of working, and the labor supply, $l_{h i}$, of individual $h$ in country $i$ is exogenous. Specifically, $l_{h i}=1$ if a person is in the labor force, and $l_{h i}=0$ for people outside the labor force. ${ }^{4}$ Those who participate in the labor force receive the wage, $w_{i}$, but they also pay taxes proportional to their wage income, $t_{i} w_{i}$.

Now, inserting (3) in (2) yields $C_{h i}=z_{h i}$. As a consequence, the indirect utility of a person in the labor force in country $i$ is given by:

$$
V_{h i}=\ln \left(\left(1-t_{i}\right) w_{i}\right)+\gamma_{0} N_{i}^{I}-\gamma_{1}\left(N_{i}^{I}\right)^{2}
$$

People outside the labor force receive social benefits, and we assume that the benefits are proportional to the wage rate, $b_{i} w_{i}$. Under this assumption, the indirect utility of a person outside the labor force becomes:

$$
V_{h i}=\ln \left(b_{i} w_{i}\right)+\gamma_{0} N_{i}^{I}-\gamma_{1}\left(N_{i}^{I}\right)^{2}
$$

\footnotetext{
${ }^{4}$ It is well known that taxes and benefits affect labour force participation, but in order to focus on immigration, we abstract from these effects.
} 
In country $i$, the number of natives is $N_{i}$, and the labor supply of natives is $L_{i}$ :

$$
L_{i}=e N_{i}
$$

where $e$ is the average employment rate of natives, which is constant across all $n$ countries. If, for example, the number of old people or children is high in the destination countries, $e$ will be small. Similarly, the labor supply by immigrants in country $i$ is given as $L_{i}^{I}$ :

$$
L_{i}^{I}=e_{i}^{I} N_{i}^{I}
$$

where $e_{i}^{I}$ is the average employment rate of immigrants in country $i$.

At the production side of the economy, we simply assume that total production is equal to the input of labor, i.e.:

$$
Y_{i}=L_{i}+L_{i}^{I}
$$

Furthermore, assuming labor and goods markets to be competitive results in zero profits, and total income in the economy is thus equal to total wage income, and $w_{i}=P_{i}$, where $P_{i}$ is the price of the good produced in country $i$.

We assume that immigrants pay taxes and receive benefits like natives, i.e. they are subject to the same taxation and benefit rules. Assuming that the public budget balances, this implies that:

$$
t_{i} w_{i}\left(L_{i}+L_{i}^{I}\right)=b_{i} w_{i}\left(N_{i}-L_{i}+N_{i}^{I}-L_{i}^{I}\right)
$$

By aggregating the demand for all consumers, and assuming that immigrants have the same demand functions as natives, total (world) demand for good $i$-i.e. the good produced in country $i$ - becomes:

$$
C_{i}=P_{i}^{-\theta} \frac{1}{n} \sum_{j=1}^{n} P_{j} Y_{j}
$$

where $Y_{j}$ is total production in country $j$, and $P_{j} Y_{j}$ is total real income of country $j$. 
Using that the (world) market for each good is assumed to clear, and that $w_{i}=P_{i}$, the equilibrium wage in country $i$ becomes:

$$
w_{i}=\left(\frac{\frac{1}{n} \sum_{j=1}^{n}\left(w_{j}\left(L+L_{j}^{I}\right)\right)}{L+L_{i}^{I}}\right)^{\frac{1}{\theta}}
$$

We see that an increase in the labor supply in country $i$ - due to immigration - lowers the wage in country $i$ (relative to the other countries), whereas an increase in the labor supply in one of the other countries will raise the wage in country $i$.

Finally, we focus exclusively on the welfare of natives. In particular, since natives in the destination countries decide on the immigration policy, we assume a utilitarian welfare function in the utilities of natives only. This function is given by:

$$
S W_{i}=e \ln \left(\left(1-t_{i}\right) w_{i}\right)+(1-e) \ln \left(b_{i} w_{i}\right)+\gamma_{0} N_{i}^{I}-\gamma_{1}\left(N_{i}^{I}\right)^{2}
$$

as $e$ is the share of natives in the labor force, and $1-e$ is the share outside the labor force.

\subsection{Immigration}

It is assumed that immigrants come from countries which do not trade with the $n$ countries in our model. This is at least partly consistent with the real world where for example EU countries have much more internal trade than trade with potential source countries of immigrants.

The destination countries decide upon the number of immigrants to accept, and, consistent with the literature, we assume that the total number of potential immigrants is sufficiently large that the destination countries receive the number of immigrants which they decide to let in. The immigrants, however, vary with respect to their labor market performance. In particular, we assume that they vary with respect to their eventual employment rate in the destination countries. Furthermore, it is assumed that immigrants respond to the policies in the destination countries; see also Borjas (1999). Thus, immi- 
grants with high employment rates prefer destination countries where wages are high and taxes are low, whereas immigrants with low employment rates prefer destination countries where benefits are high.

As far as the destination countries have information concerning the eventual employment rates of immigrants, they would (in principle) be able to condition immigration on these rates. The more interesting case, however, arises when destination countries are unable to observe employment rates before immigration or otherwise unable to condition immigration on these. To simplify the analysis, we assume that destination countries do not have any information concerning the eventual employment rate of a specific immigrant before immigration is accepted. Alternatively, our results may be interpreted as if the destination countries condition immigration on all available information concerning the employment rate of immigrants, but this information is imperfect.

Specifically, we assume that the average employment rate of immigrants in country $i$ is given as:

$$
e_{i}^{I}=f\left(e^{I}, \frac{b_{i} w_{i}}{\bar{b} \bar{w}}, \frac{\left(1-t_{i}\right) w_{i}}{(1-\bar{t}) \bar{w}}\right), \quad f \in[0,1]
$$

where $\bar{b} \bar{w}$ and $(1-\bar{t}) \bar{w}$ are the average level of benefits and after tax wages, respectively, in all other destination countries than country $i$, and $e^{I}$ is the average employment rate of all potential immigrants.

If all destination countries pursue the same welfare policies, and gross wages are equal, the average employment rate of immigrants will be the same in all destination countries:

$$
f\left(e^{I}, 1,1\right)=e^{I}
$$

Furthermore, we assume that:

$$
f_{2}^{\prime} \leq 0 \quad \text { and } \quad f_{3}^{\prime} \geq 0
$$

Thus, if $b_{i}$ is increased relative to $\bar{b}$, there is a decrease in the employment rate of potential immigrants to country $i$, as immigrants with low employment rates will tend to favour 
country $i$. In contrast, if country $i$ increases the after tax rate, $1-t_{i}$, relative to the after tax rates in other destination countries, the average employment rate of potential immigrants to country $i$ increases, as immigrants with high employment rates will find country $i$ more attractive.

Finally, we shall assume that when $b_{i} w_{i}=\bar{b} \bar{w}$ and $\left(1-t_{i}\right) w_{i}=(1-\bar{t}) \bar{w}$, the elasticities of the employment rate, $e_{i}^{I}$, with respect to $b_{i}$ and $1-t_{i}$ are given by $-\alpha$ and $\alpha$, respectively: ${ }^{5}$

$$
\begin{aligned}
& f_{2}^{\prime}\left(e^{I}, 1,1\right)=-\alpha \cdot e^{I} \\
& f_{3}^{\prime}\left(e^{I}, 1,1\right)=\alpha \cdot e^{I}
\end{aligned}
$$

\subsection{Game Structure}

The immigration policy as well as welfare policies in one country have implications for other countries. Therefore, policy determination can be seen as a game between the destination countries. Since our focus is on the implication of coordinating immigration policies, we are going to consider two different scenarios. A solution with uncoordinated immigration policies and a solution where immigration policies are coordinated:

1. Uncoordinated policies: The countries simultaneously and unilaterally determine $t_{i}$, $b_{i}$ and $N_{i}$. The outcome is assumed to be a Nash equilibrium.

2. Coordinated immigration policies: First, all destination countries agree on a binding level of immigration for all countries, $N_{i}^{I}=N^{I}, i=1, \ldots, n$. Thereafter, the countries simultaneously and unilaterally determine $t_{i}$ and $b_{i}$. The outcome of stage 2 is assumed to be a Nash equilibrium.

\footnotetext{
${ }^{5}$ Allowing the elasticities w.r.t. $b_{i}$ and $1-t_{i}$ to differ would have no qualitative effects on the results.
} 


\section{Results}

It is tedious but relatively straightforward to solve the model in the two cases, and, therefore, the details concerning the solutions are relegated to an appendix. In the case of uncoordinated policies, each country maximizes social welfare with respect to $t_{i}, b_{i}$ and $N_{i}^{I}$ - given immigration and welfare policies in the other countries. ${ }^{6}$ The Nash equilibrium is found by using that countries are symmetric, and, therefore, immigration and welfare policies will be symmetric in equilibrium.

In the case of coordinated immigration policies, the model is solved in two stages by applying backwards induction. First, we solve the second stage problem, where each country maximizes welfare with respect to taxes and benefits - given the level of immigration as well as taxes and benefits in the other countries. By using symmetry, we find a Nash equilibrium in taxes and benefits. Second, we solve the first stage problem where the coordinated immigration policy is determined. This is done by maximizing the welfare of a representative country with respect to a common level of immigration in all countries, and using that taxes and benefits depend on immigration as found in the second stage. See the appendix for details.

It turns out that the implications of coordinating immigration policies are in general ambiguous. Therefore, we consider two special cases of the model which simplify the analysis considerably, but are sufficient to illustrate the mechanisms of the model. In the first case, we assume that immigrants do not respond to welfare policies in destination countries. In equilibrium, this corresponds to assuming that $\alpha=0$ in (17)-(18). This implies that the average employment rate of immigrants in all destination countries is always $e^{I}$, although this rate may be different from the employment rate of natives.

In the second special case, we assume that the average employment rate of immigrants is equal to the average employment rate of natives in the destination countries, $e^{I}=e$, but now the employment rate of immigrants to a particular destination country, $e_{i}^{I}$, depends

\footnotetext{
${ }^{6}$ In solving the optimization problem of country $i$, we assume that country $i$ ignores the effect that a change in $N_{i}^{I}$ has on world demand in (11). This is a standard assumption when the number of countries is relatively large and simplifies the analytics considerably. Changing it would have no qualitative effects on the results.
} 
on the welfare policies of this country relative to other countries as specified in (14).

Throughout, we only consider parameter values for which interior solutions exist. ${ }^{7}$

\subsection{Special Case 1}

In this case, we assume that $f_{2}^{\prime}=f_{3}^{\prime}=0$. That is, immigrants do not react to the welfare policies of destination countries. By comparing the solutions of the model in the cases of uncoordinated and coordinated policies, we find the results reported in the following proposition, where superscripts " $U$ " and " $C$ " refer to the outcomes under uncoordinated and coordinated policies, respectively:

Proposition 1 If $f_{2}^{\prime}=f_{3}^{\prime}=0$, then:

$$
\begin{aligned}
N^{I U} & <N^{I C} \\
t^{U} & =t^{C} \\
b^{U} & \gtreqless b^{C} \text { if } e \gtreqless e^{I} \\
S W^{U} & <S W^{C}
\end{aligned}
$$

Proof: See appendix.

In this case, coordination of immigration policies always gives rise to more immigration. This is so because immigration into one country leads to a deterioration of the terms of trade of this country. In the case of coordinated immigration policies, this terms of trade externality (or spill-over) is neutralized, and the implication is an increase in the level of immigration. Since the concern for the terms of trade effect restrains immigration in the case of uncoordinated policies, social welfare increases as a result of coordination.

We also see that the level of social benefits depends on whether or not immigration policies are coordinated. If the employment rate of immigrants is lower than the employment rate of natives, $e^{I}<e$, the higher immigration under coordination implies that

\footnotetext{
${ }^{7}$ Note that the existence of interior solutions can be ensured by appropriate choices of $\gamma_{0}$ and $\gamma_{1}$.
} 
there is a decrease in social benefits, $b^{C}<b^{U}$, and vice versa if the employment rate of immigrants is higher than the employment rate of natives. There are two reasons why a lower employment rate of immigrants gives rise to lower benefits. First, with $e^{I}<e$, immigrants are more costly for the public sector than natives which implies that social benefits must be diminished. This is a kind of income effect. Second, since social welfare only depends on the income of natives, it is optimal to shift some income from recipients of social benefits (where the share of immigrants is relatively high) to income for tax payers (where the share of immigrants is relatively low). This is a kind of substitution effect.

The tax rate does not depend on whether immigration policies are coordinated. This is a result of two counteracting effects on the tax level. First, if $e^{I}<e$, immigrants are more costly for the public sector, which tends to increase taxes. Second, when $e^{I}<e$, the share of immigrants is relatively low among tax payers, which tends to decrease taxes for the same reason as benefits are lowered in this case (see above). In the model these two effects are quantitatively of the exact same size implying that taxes are unaffected by immigration policies being coordinated rather than uncoordinated. When $e<e^{I}$, the same intuition applies with opposite effects.

Finally, coordination of immigration policies affects the income distribution since social benefits are affected whereas taxes are unchanged. If the employment rate of immigrants is lower than the employment rate of natives, the receivers of social benefits will tend to lose on coordination as benefits are lower, ${ }^{8}$ whereas they will gain more than others if the employment rate of immigrants is higher than the employment rate of natives. That natives with characteristics similar to those of immigrants tend to lose (relatively) on immigration is a well-known result from the literature on labor market effects of immigration; see, e.g., Borjas (2003) and Zorlu and Hartog (2005). Typically, however, the loss comes about through lower wages or displacement effects, as immigrants compete with similar natives for jobs. In the present case, the reason is somewhat different, as

\footnotetext{
${ }^{8}$ Despite lower benefits, they may in fact gain on coordination through a larger direct utility from immigration.
} 
the natives most similar to the immigrants lose on more immigration and hence coordination because benefits and taxes are changed to optimally target the groups where natives dominate.

\subsection{Special Case 2}

In this case, we assume that the average employment rate of immigrants equals the average employment rate of natives, $e^{I}=e$, but the employment rate of immigrants to a particular country depends on the policy in that country as given by (14). This introduces an additional externality (or spill-over) between the countries - a welfare policy externality.

By solving the model under these assumptions, we find the results reported in the following proposition:

Proposition 2 If $e^{I}=e$, there exist a value $\hat{\theta}$ such that:

1. If $\theta<\hat{\theta}$, then:

$$
\begin{aligned}
N^{I U} & <N^{I C} \\
t^{U} & >t^{C} \\
b^{U} & >b^{C} \\
S W^{U} & <S W^{C}
\end{aligned}
$$

2. If $\theta>\hat{\theta}$, then:

$$
\begin{aligned}
N^{I U} & >N^{I C} \\
t^{U} & <t^{C} \\
b^{U} & <b^{C} \\
S W^{U} & <S W^{C}
\end{aligned}
$$

Proof: See appendix. 
If the price elasticity of demand is low, $\theta<\hat{\theta}$, the terms of trade externality is the dominating externality, and coordination of immigration policies then still gives rise to an increase in immigration. As in Proposition 1, the reason is that the terms of trade effect is neutralized in the case of coordinated policies.

When $\theta$ increases, the importance of the terms of trade externality becomes smaller. This implies that immigration in the uncoordinated case increases towards the coordinated level. However, the increase in $\theta$ will also intensify fiscal competition for immigrants in both the uncoordinated and the coordinated cases as the negative wage effects of this fiscal competition are now smaller. ${ }^{9}$ This competition is socially inoptimal since in equilibrium, the distribution of immigrants is unchanged, but natives outside the labor force have been hurt by the fiscal competition (a distributional cost). This in turn leads to less immigration in the case of coordinated policies, as less immigration will serve to reduce this fiscal competition. That less immigration will reduce fiscal competition follows from the fact that with less immigration, the distributional costs for natives of using fiscal competition are relatively higher. Consequently, when $\theta>\hat{\theta}$, the welfare policy externality is dominating, and the destination countries agree on less immigration in the coordinated case to diminish the increased socially inoptimal fiscal competition.

Under the condition that the terms of trade effect is dominating, $\theta<\hat{\theta}$, the higher immigration under coordination implies that there will be more competition over attracting immigrants with a high employment rate, and, therefore, taxes and benefits will be lower. With respect to social welfare, there are two counteracting effects. On the one hand, there is more immigration, and since the level of immigration tends to be inefficiently low for uncoordinated policies, this tends to imply that social welfare is higher in the case of coordinated policies. On the other hand, the more severe competition in welfare policies, due to coordination, tends to decrease welfare. Since coordination can always do at least as good as the the uncoordinated outcome, the former effect dominates. Furthermore, since taxes as well as benefits are lower in the case of coordinated policies, there is an un-

\footnotetext{
${ }^{9}$ Fiscal competition has negative terms of trade (wage) effects because it increase the labour supply of immigrants for a given level of immigration.
} 
ambiguous effect on the income distribution in the destination countries. The tax payers are going to gain on coordination, whereas the receivers of benefits are going to lose.

If the welfare policy externality is dominating, $\theta>\hat{\theta}$, the level of immigration is lower under coordinated policies. This implies that taxes and social benefits are higher in the coordinated case than in the uncoordinated case. Again these are two counteracting effects on welfare, but in this case, the latter dominates, which results in higher welfare under coordination. Furthermore, the effects on the income distribution from coordination is now reversed compared to the situation with $\theta<\hat{\theta}$ : The reduced fiscal competition under coordination benefits the recipients of benefits while harming the tax payers.

\section{Conclusion}

We have considered the implications of coordination of immigration policies among a group of destination countries in a model with two types of externalities between these countries - a terms of trade externality and a welfare policy externality.

We find that coordination unambiguously increases social welfare in destination countries. The reason is that coordination internalizes (some of) the externalities from immigration policies. However, it is ambiguous whether coordination gives rise to more or less immigration and thus helps to solve the overall coordination problem between source and destination countries.

If the terms of trade externality is dominating, coordination induces more immigration, as coordination internalizes this externality. However, if the welfare policy externality is the dominating externality, coordination reduces immigration. The reason is that coordination of immigration policies cannot fully internalize the welfare policy externality, but as a second best response, the coordinating countries choose to reduce immigration to minimize the socially harmful fiscal competition.

Therefore, as far as the level of immigration is too low as seen in a more global perspective where we also take the welfare of citizens in the source countries into account, coordination of immigration policies among destination countries may give rise to both 
higher and lower world wide welfare.

Finally, coordination of immigration policies also affect the income distributions in the destination countries, i.e. the distribution of income between people in the labor force and people outside the labor force. The latter will lose on coordination if: i) immigrants have relatively low employment rates, in which case public policy will be directed towards the relatively more important group of tax payers under a coordinated outcome; and/or ii) the price elasticity of demand is low, in which case they will become the victims of an increased immigration and associated tax competition in a coordinated regime. 


\section{A Solving the Policy Game}

In Subsection A.1, we solve the policy game in the case of uncoordinated immigration policies. We first derive (indirect) solutions for the general model, and then provide more explicit solutions for the two special cases considered in the paper. Similarly, Subsection A.2 provides solutions for the case of coordinated policies. Throughout, we assume that parameter values are such that interiour solutions exist.

\section{A.1 Uncoordinated Policies}

In the case of uncoordinated policies, each country maximizes social welfare given immigration and welfare policies in the other countries. We assume that the countries simultaneously and unilaterally determine the benefit level, tax rate and number of immigrants. That is, country $i$ maximizes:

$$
S W_{i}=e \ln \left(\left(1-t_{i}\right) w_{i}\right)+(1-e) \ln \left(b_{i} w_{i}\right)+\gamma_{0} N_{i}^{I}-\gamma_{1}\left(N_{i}^{I}\right)^{2}
$$

with respect $b_{i}, t_{i}$ and $N_{i}^{I}$, and subject to the public budget constraint:

$$
t_{i} w_{i}\left(L_{i}+L_{i}^{I}\right)=b_{i} w_{i}\left(N_{i}-L_{i}+N_{i}^{I}-L_{i}^{I}\right)
$$

where $e_{i}^{I}$ is given by (14), and taking as given the choices of the $n-1$ other countries.

The solution to this optimization problem can be found by use of the Lagrangian:

$$
\begin{aligned}
L_{i}= & e \ln \left(1-t_{i}\right)+(1-e) \ln b_{i}+\ln w_{i}+\gamma_{0} N_{i}^{I}-\gamma_{1}\left(N_{i}^{I}\right)^{2} \\
& -\lambda\left(\left(x_{i}-1\right) b_{i}-t_{i}\right)
\end{aligned}
$$

where $x_{i}=\left(N_{i}+N_{i}^{I}\right) /\left(L_{i}+L_{i}^{I}\right)$ and $\lambda$ is the Lagrange multiplier. The first-order conditions of (A3) with respect to $b_{i}, t_{i}, N_{i}^{I}$ and $\lambda$ are given by:

$$
\begin{aligned}
& \frac{\partial L_{i}}{\partial b_{i}}=\frac{1-e}{b_{i}}+\frac{1}{w_{i}} \frac{\partial w_{i}}{\partial b_{i}}-\lambda\left(\frac{\partial x_{i}}{\partial b_{i}} b_{i}+\left(x_{i}-1\right)\right)=0 \\
& \frac{\partial L_{i}}{\partial t_{i}}=-\frac{e}{1-t_{i}}+\frac{1}{w_{i}} \frac{\partial w_{i}}{\partial t_{i}}-\lambda\left(\frac{\partial x_{i}}{\partial t_{i}} b_{i}-1\right)=0
\end{aligned}
$$




$$
\begin{aligned}
\frac{\partial L_{i}}{\partial N_{i}^{I}} & =\frac{1}{w_{i}} \frac{\partial w_{i}}{\partial N_{i}^{I}}-\lambda \frac{\partial x_{i}}{\partial N_{i}^{I}} b_{i}+\gamma_{0}-2 \gamma_{1} N_{i}^{I}=0 \\
\frac{\partial L_{i}}{\partial \lambda} & =-\left(x_{i}-1\right) b_{i}+t_{i}=0
\end{aligned}
$$

with:

$$
\begin{aligned}
\frac{\partial w_{i}}{\partial b_{i}} & =-\frac{w_{i} f_{2}^{\prime}\left(e^{I}, \frac{b_{i} w_{i}}{b \bar{w}}, \frac{\left(1-t_{i}\right) w_{i}}{(1-\bar{t}) \bar{w}}\right) w_{i} N_{i}^{I}}{\theta Y_{i} \bar{b} \bar{w}} \\
\frac{\partial x_{i}}{\partial b_{i}} & =-\frac{\left(N_{i}+N_{i}^{I}\right) f_{2}^{\prime}\left(e^{I}, \frac{b_{i} w_{i}}{b \bar{w}}, \frac{\left(1-t_{i}\right) w_{i}}{(1-\bar{t}) \bar{w}}\right) w_{i} N_{i}^{I}}{Y_{i}^{2} \bar{b} \bar{w}} \\
\frac{\partial w_{i}}{\partial t_{i}} & =\frac{w_{i} f_{3}^{\prime}\left(e^{I}, \frac{b_{i} w_{i}}{b \bar{w}}, \frac{\left(1-t_{i}\right) w_{i}}{(1-\bar{t}) \bar{w}}\right) w_{i} N_{i}^{I}}{\theta Y_{i}(1-\bar{t}) \bar{w}} \\
\frac{\partial x_{i}}{\partial t_{i}} & =\frac{\left(N_{i}+N_{i}^{I}\right) f_{3}^{\prime}\left(e^{I}, \frac{b_{i} w_{i}}{b \bar{w}}, \frac{\left(1-t_{i}\right) w_{i}}{(1-\bar{t}) \bar{w}}\right) w_{i} N_{i}^{I}}{Y_{i}^{2}(1-\bar{t}) \bar{w}} \\
\frac{\partial w_{i}}{\partial N_{i}^{I}} & =-\frac{w_{i} f\left(e^{I}, \frac{b_{i} w_{i}}{b \bar{w}}, \frac{\left(1-t_{i}\right) w_{i}}{(1-\bar{t}) \bar{w}}\right)}{\theta Y_{i}} \\
\frac{\partial x_{i}}{\partial N_{i}^{I}} & =\frac{Y_{i}-\left(N_{i}+N_{i}^{I}\right) f\left(e^{I}, \frac{b_{i} w_{i}}{b \bar{w}}, \frac{\left(1-t_{i}\right) w_{i}}{(1-\bar{t}) \bar{w}}\right)}{Y_{i}^{2}}
\end{aligned}
$$

Using that policies and the equilibrium more generally are symmetric across countries, i.e. $b_{i}=\bar{b}=b, t_{i}=\bar{t}=t, N_{i}^{I}=N^{I}, w_{i}=\bar{w}=w$, and $Y_{i}=Y$, we can rewrite (A8)-(A13) as:

$$
\begin{aligned}
\frac{\partial w}{\partial b} & =\frac{w \alpha L^{I}}{\theta Y b} \\
\frac{\partial x}{\partial b} & =\frac{\left(N+N^{I}\right) \alpha L^{I}}{Y^{2} b} \\
\frac{\partial w}{\partial t} & =\frac{w \alpha L^{I}}{\theta Y(1-t)} \\
\frac{\partial x}{\partial t} & =\frac{\left(N+N^{I}\right) \alpha L^{I}}{Y^{2}(1-t)} \\
\frac{\partial w}{\partial N^{I}} & =-\frac{w e^{I}}{\theta Y} \\
\frac{\partial x}{\partial N^{I}} & =\frac{Y-\left(N+N^{I}\right) e^{I}}{Y^{2}}
\end{aligned}
$$

By substituting (A14)-(A19) into (A4)-(A7), and after some manipulations, we get the 
following four equations, which determine the equilibrium valus of $t, b, N^{I}$ and $\lambda$ :

$$
\begin{aligned}
\frac{1-e}{b}+\frac{\alpha L^{I}}{\theta Y b}-\lambda\left(\frac{\left(N+N^{I}\right) \alpha L^{I}}{Y^{2}}+(x-1)\right) & =0 \\
-\frac{e}{1-t}+\frac{\alpha L^{I}}{\theta Y(1-t)}-\lambda\left(\frac{\left(N+N^{I}\right) \alpha L^{I}}{Y^{2}(1-t)} b-1\right) & =0 \\
-\frac{e^{I}}{\theta Y}-\lambda\left(\frac{Y-\left(N+N^{I}\right) e^{I}}{Y^{2}} b\right)+\gamma_{0}-2 \gamma_{1} N^{I} & =0 \\
-(x-1) b+t & =0
\end{aligned}
$$

In the general case, it is not possible to solve this system of equations more explicitly for the equilibrium values of $b, t$ and $N^{I}$. To do this, we consider two special cases of the model.

\section{A.1.1 Special Case 1}

In the first special case, $\alpha=0$. That is, we assume that immigrants do not respond to welfare policies in destination countries. In this case, (A20)-(A23) above yield the following expressions:

$$
\begin{aligned}
\frac{1-e}{b}-\lambda(x-1) & =0 \\
-\frac{e}{1-t}+\lambda & =0 \\
-\frac{e^{I}}{\theta Y}-\lambda\left(\frac{Y-\left(N+N^{I}\right) e^{I}}{Y^{2}} b\right)+\gamma_{0}-2 \gamma_{1} N^{I} & =0 \\
-(x-1) b+t & =0
\end{aligned}
$$

From (A24)-(A27), it is now possible to derive the equilibirum benefit level, tax rate and number of immigrants (the latter only indirectly) in destination country $i$ in the case of uncoordinated policies:

$$
\begin{aligned}
b^{U} & =\frac{1-e}{x-1} \\
t^{U} & =1-e \\
N^{I U} & =\frac{\gamma_{0}-\frac{e^{I}}{\theta Y}-\frac{(1-e)\left(e-e^{I}\right) N}{Y\left[(1-e) N+\left(1-e^{I}\right) N^{I U}\right]}}{2 \gamma_{1}}
\end{aligned}
$$




\section{A.1.2 Special Case 2}

In the second special case, we assume that the average employment rate of immigrants is equal to the average employment rate of natives in the destination countries, i.e. $e^{I}=e$. Using this assumption, the general solutions in (A20)-(A23) becomes:

$$
\begin{aligned}
\frac{1-e}{b}+\frac{\alpha N^{I}}{\theta b\left(N+N^{I}\right)}-\lambda\left(\frac{\alpha N^{I}+(x-1) Y}{Y}\right) & =0 \\
-\frac{e}{1-t}+\frac{\alpha N^{I}}{\theta\left(N+N^{I}\right)(1-t)}-\lambda\left(\frac{\alpha N^{I} b-Y(1-t)}{Y(1-t)}\right) & =0 \\
-\frac{1}{\theta\left(N+N^{I}\right)}+\gamma_{0}-2 \gamma_{1} N^{I} & =0 \\
-(x-1) b+t & =0
\end{aligned}
$$

Solving (A31)-(A34) with respect to $b, t$ and $N^{I}$ gives the following expressions for the benefit level, tax rate and number of immigrants (the latter only indirectly) in destination country $i$ :

$$
\begin{aligned}
b^{U} & =\frac{(1-e) \theta Y+\alpha N^{I U} e}{\theta\left(\alpha N^{I U}+(x-1) Y\right)} \\
t^{U} & =\frac{(x-1)\left[(1-e) \theta Y+\alpha N^{I U} e\right]}{\theta\left(\alpha N^{I U}+(x-1) Y\right)} \\
N^{I U} & =\frac{\gamma_{0}}{2 \gamma_{1}}-\frac{1}{2 \gamma_{1} \theta\left(N+N^{I U}\right)}
\end{aligned}
$$

\section{A.2 Coordinated Policies}

In the case of coordinated immigration policies, the model is solved in two stages by applying backwards induction. First, we solve the second stage, where each country maximizes welfare with respect to benefits and taxes $\left(b_{i}\right.$ and $\left.t_{i}\right)$ given the coordinated level of immigration into each country $\left(N_{i}^{I}=N^{I}\right)$ as well as benefits, taxes and wages in the other countries. Then, given the equilibrium in the second stage, we solve the first stage by maximizing the welfare of a representative country with respect to a common level of immigration in all countries $\left(N^{I}\right)$, using that the equilibrium values of benefits and taxes depend on immigration as found in the second stage.

Starting at the second stage, we use (A3) - and the assumption of a common level of 
immigration in all countries - to write the Lagrangian of the second stage optimization problem as:

$$
\begin{aligned}
L_{i}= & e \ln \left(1-t_{i}\right)+(1-e) \ln b_{i}+\ln w_{i}+\gamma_{0} N^{I}-\gamma_{1}\left(N^{I}\right)^{2} \\
& -\lambda\left((x-1) b_{i}-t_{i}\right)
\end{aligned}
$$

where $x_{i}=\left(N_{i}+N_{i}^{I}\right) /\left(L_{i}+L_{i}^{I}\right)$ and $\lambda$ is the Lagrange multiplier.. The first order conditions of (A38) with respect to $b_{i}, t_{i}$ and $\lambda$ are now:

$$
\begin{aligned}
\frac{\partial L_{i}}{\partial b_{i}} & =\frac{1-e}{b_{i}}+\frac{1}{w_{i}} \frac{\partial w_{i}}{\partial b_{i}}-\lambda\left(\frac{\partial x_{i}}{\partial b_{i}} b_{i}+\left(x_{i}-1\right)\right)=0 \\
\frac{\partial L_{i}}{\partial t_{i}} & =-\frac{e}{1-t_{i}}+\frac{1}{w_{i}} \frac{\partial w_{i}}{\partial t_{i}}-\lambda\left(\frac{\partial x_{i}}{\partial t_{i}} b_{i}-1\right)=0 \\
\frac{\partial L_{i}}{\partial \lambda} & =-\left(x_{i}-1\right) b_{i}+t_{i}=0
\end{aligned}
$$

with:

$$
\begin{aligned}
\frac{\partial w_{i}}{\partial b_{i}} & =-\frac{w_{i} f_{2}^{\prime}\left(e^{I}, \frac{b_{i} w_{i}}{b \bar{w}}, \frac{\left(1-t_{i}\right) w_{i}}{(1-\bar{t}) \bar{w}}\right) w_{i} N_{i}^{I}}{\theta Y_{i} \bar{b} \bar{w}} \\
\frac{\partial x_{i}}{\partial b_{i}} & =-\frac{\left(N_{i}+N_{i}^{I}\right) f_{2}^{\prime}\left(e^{I}, \frac{b_{i} w_{i}}{b \bar{w}}, \frac{\left(1-t_{i}\right) w_{i}}{(1-\bar{t}) \bar{w}}\right) w_{i} N_{i}^{I}}{Y_{i}^{2} \bar{b} \bar{w}} \\
\frac{\partial w_{i}}{\partial t_{i}} & =\frac{w_{i} f_{3}^{\prime}\left(e^{I}, \frac{b_{i} w_{i}}{b \bar{w}}, \frac{\left(1-t_{i}\right) w_{i}}{(1-\bar{t}) \bar{w}}\right) w_{i} N_{i}^{I}}{\theta Y_{i}(1-\bar{t}) \bar{w}} \\
\frac{\partial x_{i}}{\partial t_{i}} & =\frac{\left(N_{i}+N_{i}^{I}\right) f_{3}^{\prime}\left(e^{I}, \frac{b_{i} w_{i}}{b \bar{w}}, \frac{\left(1-t_{i}\right) w_{i}}{(1-\bar{t}) \bar{w}}\right) w_{i} N_{i}^{I}}{Y_{i}^{2}(1-\bar{t}) \bar{w}}
\end{aligned}
$$

Using symmetry across countries, we rewrite (A42)-(A45) as:

$$
\begin{aligned}
\frac{\partial w}{\partial b} & =\frac{w \alpha L^{I}}{\theta Y b} \\
\frac{\partial x}{\partial b} & =\frac{\left(N+N^{I}\right) \alpha L^{I}}{Y^{2} b} \\
\frac{\partial w}{\partial t} & =\frac{w \alpha L^{I}}{\theta Y(1-t)} \\
\frac{\partial x}{\partial t} & =\frac{\left(N+N^{I}\right) \alpha L^{I}}{Y^{2}(1-t)}
\end{aligned}
$$


By substituting (A46)-(A49) into (A39)-(A41), we get the following equations:

$$
\begin{aligned}
\frac{1-e}{b}+\frac{\alpha L^{I}}{\theta Y b}-\lambda\left(\frac{\left(N+N^{I C}\right) \alpha L^{I}}{Y^{2}}+(x-1)\right) & =0 \\
-\frac{e}{1-t}+\frac{\alpha L^{I}}{\theta Y(1-t)}-\lambda\left(\frac{\left(N+N^{I C}\right) \alpha L^{I}}{Y^{2}(1-t)} b-1\right) & =0 \\
-(x-1) b+t & =0
\end{aligned}
$$

Again, we cannot derive more explicit solutions for $b$ and $t$ (and $N^{I}$ in the first stage) in the general case. Instead, we consider the two special cases of the model.

\section{A.2.1 Special Case 1}

Assuming that $\alpha=0$, we can easily derive the benefit level and tax rate from (A50)-(A52) in the case of coordinated policies:

$$
\begin{aligned}
b^{C} & =\frac{1-e}{x-1} \\
t^{C} & =1-e
\end{aligned}
$$

Given these benefits and taxes, we can then solve the first stage of the model by maximizing the social welfare in a representative country with respect to a common level of immigration. Formally, we insert (A53) and (A54) into the social welfare function. This gives the expression:

$$
S W_{i}=e \ln (e)+(1-e) \ln \left(\frac{1-e}{x-1}\right)+\gamma_{0} N^{I}-\gamma_{1}\left(N^{I}\right)^{2}
$$

Now, the representative country chooses $N^{I}$ to maximize (A55). After some manipulations, this gives the following (indirect) expression for the optimal level of immigration in the first stage of the model:

$$
N^{I C}=\frac{\gamma_{0}-\frac{(1-e)\left(e-e^{I}\right) N}{Y\left[(1-e) N+\left(1-e^{I}\right) N^{I C}\right]}}{2 \gamma_{1}}
$$




\section{A.2.2 Special Case 2}

In the second case, we assume that $e^{I}=e$. This results in the following expressions for $b$ and $t$ :

$$
\begin{aligned}
b^{C} & =\frac{(1-e) \theta Y+\alpha N^{I C} e}{\theta\left(\alpha N^{I C}+(x-1) Y\right)} \\
t^{C} & =\frac{(x-1)\left[(1-e) \theta Y+\alpha N^{I C} e\right]}{\theta\left(\alpha N^{I C}+(x-1) Y\right)}
\end{aligned}
$$

Using the same procedure as in the special case above, we insert (A57) and (A58) into the social welfare function, which can then be written as:

$$
\begin{aligned}
& S W_{i}=e \ln \left(\frac{\theta \alpha N^{I}-(x-1)\left(\theta Y e+\alpha N^{I} e\right)}{\theta\left(\alpha N^{I}+(x-1) Y\right)}\right) \\
&+(1-e) \ln \left(\frac{(1-e) \theta Y+\alpha N^{I} e}{\theta\left(\alpha N^{I}+(x-1) Y\right)}\right)+\gamma_{0} N^{I}-\gamma_{1}\left(N^{I}\right)^{2}
\end{aligned}
$$

To derive the number of immigrants, the representative country chooses $N^{I}$ in the first stage of the model to maximize (A59), which - after some manipulations - results in the following level of immigration:

$$
N^{I C}=\frac{\gamma_{0}}{2 \gamma_{1}}+\frac{\alpha N(\theta-1)(1-e)^{2} e(B-A)}{2 \gamma_{1} A B\left[\alpha N^{I C}+(x-1) Y\right]}
$$

where $A=\alpha N^{I C}(\theta-(1-e))+e \theta(x-1) Y$ and $B=(1-e) \theta Y+\alpha N^{I C} e$.

\section{B Proofs of Propositions}

Subsection B.1 contains a proof of Proposition 1 in the paper, whereas Subsection B.2 provides a proof of Proposition 2 from the paper.

\section{B.1 Proof of Proposition 1}

Proposition 1 from the paper states:

Proposition 3 If $\alpha=0$, then:

$$
\begin{aligned}
N^{I U} & <N^{I C} \\
t^{U} & <t^{C} \\
b^{U} & \gtreqless b^{C} \text { if } e \gtreqless e^{I} \\
S W^{U} & <S W^{C}
\end{aligned}
$$


Proof. From the coordinated solution, we have the following first-order condition (by differentiation of (A55) with respect to $\left.N^{I}\right)$ :

$$
\frac{\partial S W}{\partial N^{I}}=\gamma_{0}-\frac{(1-e)\left(e-e^{I}\right) N}{Y\left[(1-e) N+\left(1-e^{I}\right) N^{I}\right]}-2 \gamma_{1} N^{I}=0
$$

for $N^{I}=N^{I C}$, where $Y=e N+e^{I} N^{I}$. Furthermore, the second order condition yields:

$$
\begin{aligned}
\frac{\partial^{2} S W}{\partial\left(N^{I}\right)^{2}} & =\frac{(1-e)\left(e-e^{I}\right) N}{Y\left[(1-e) N+\left(1-e^{I}\right) N^{I}\right]}\left[\frac{e^{I}}{Y}+\frac{1-e^{I}}{(1-e) N+\left(1-e^{I}\right) N^{I}}\right] \\
-2 \gamma_{1} N^{I} & <0
\end{aligned}
$$

for $N^{I}=N^{I C}$. Since the first term is decreasing (numerically) in $N^{I}$ but does not change sign as $N^{I}$ increases above $N^{I C}$, it follows that the second derivative is negative for all $N^{I} \geq N^{I C}$. This in turn implies that:

$$
\gamma_{0}-\frac{(1-e)\left(e-e^{I}\right) N}{Y\left[(1-e) N+\left(1-e^{I}\right) N^{I}\right]}-2 \gamma_{1} N^{I} \leq 0
$$

for all $N^{I} \geq N^{I C}$.

The first-order condition for $N^{I}$ from the uncoordinated solution is:

$$
\gamma_{0}-\frac{(1-e)\left(e-e^{I}\right) N}{Y\left[(1-e) N+\left(1-e^{I}\right) N^{I}\right]}-2 \gamma_{1} N^{I}=\frac{e^{I}}{\theta Y}
$$

We know from above that the left hand side is non-positive for $N^{I} \geq N^{I C}$. Since the right hand side is always positive, it follows that $N^{I U}<N^{I C}$. This proves the first part of Proposition 1.

The second part of Proposition 1, $t^{U}=t^{C}$, follows directly from (A29) and (A54). Furthermore, from the expressions for $b$ in (A28) and (A53), it follows that:

$$
\frac{\partial b}{\partial N^{I}}=\frac{(1-e)\left(e^{I}-e\right) N}{\left[(1-e) N+\left(1-e^{I}\right) N^{I}\right]^{2}}
$$

and hence that $\frac{\partial b}{\partial N^{I}} \gtreqless 0$ if $e^{I} \gtreqless e$. Combined with $N^{I U}<N^{I C}$, this proves the third part of Proposition 1.

The final part of Proposition 1 is proved by noticing that, since the expressions for optimal choices of $b$ and $t$ as functions of $N^{I}$ are identical in the two policy cases, the uncoordinated solution can always be attained in the coordinated case. Since a different 
solution is in fact chosen in the coordinated case, $N^{I C}$ is revealed preferred to $N^{I U}$, and it therefore follows that $S W^{U}<S W^{C}$.

\section{B.2 Proof of Proposition 2}

Proposition 2 from the paper states:

Proposition 4 If $e^{I}=e$, there exist $\hat{\theta}$ such that:

1. If $\theta<\hat{\theta}$, then:

$$
\begin{aligned}
N^{I U} & <N^{I C} \\
t^{U} & >t^{C} \\
b^{U} & >b^{C} \\
S W^{U} & <S W^{C}
\end{aligned}
$$

2. If $\theta>\hat{\theta}$, then:

$$
\begin{aligned}
N^{I U} & >N^{I C} \\
t^{U} & <t^{C} \\
b^{U} & <b^{C} \\
S W^{U} & <S W^{C}
\end{aligned}
$$

Proof. The proof of the part concerning $N^{I}$ contains the following three steps:

1. First, we show that when $\theta \rightarrow 1$, then $N^{I U}<\frac{\gamma_{0}}{2 \gamma_{1}}$ and $N^{I C}=\frac{\gamma_{0}}{2 \gamma_{1}}$, which means that $N^{I U}<N^{I C}$ when $\theta=1$.

2. Second, we show that when $\theta \rightarrow \infty$, then $N^{I U}=\frac{\gamma_{0}}{2 \gamma_{1}}$ and $N^{I C}<\frac{\gamma_{0}}{2 \gamma_{1}}$, which means that $N^{I U}>N^{I C}$ when $\theta=\infty$.

3. To show uniqueness of $\hat{\theta}$, it is sufficient to show that $\frac{\partial N^{I U}}{\partial \theta}>0$ and $\frac{\partial N^{I C}}{\partial \theta}<0$. Then we know that $N^{I C}$ and $N^{U C}$ can only cross once (at $\hat{\theta}$ ).

Re. 1: Consider equations (A37) and (A60) derived in the second special case of the model:

$$
\begin{aligned}
N^{I U} & =\frac{\gamma_{0}}{2 \gamma_{1}}-\frac{1}{2 \gamma_{1} \theta\left(N+N^{I U}\right)} \\
N^{I C} & =\frac{\gamma_{0}}{2 \gamma_{1}}+\frac{\alpha N(\theta-1)(1-e)^{2} e(B-A)}{2 \gamma_{1} A B\left[\alpha N^{I C}+(x-1) Y\right]}
\end{aligned}
$$


where $A=\alpha N^{I C}(\theta-(1-e))+e \theta(x-1) Y$ and $B=(1-e) \theta Y+\alpha N^{I C} e$.

By setting $\theta=1$, we obtain the following expressions for the level of immigration in case of uncoordinated and coordinated policies, respectively:

$$
\begin{aligned}
N^{I U} & =\frac{\gamma_{0}}{2 \gamma_{1}}-\frac{1}{2 \gamma_{1}\left(N+N^{I U}\right)}<\frac{\gamma_{0}}{2 \gamma_{1}} \\
N^{I C} & =\frac{\gamma_{0}}{2 \gamma_{1}}
\end{aligned}
$$

from which follows that $N^{I U}<N^{I C}$ when $\theta=1$.

Re. 2: In the second step of the proof, we assume that $\theta \rightarrow \infty$. Substituting this assumption into (A66), the level of immigration for uncoordinated policies becomes:

$$
N^{I U}=\frac{\gamma_{0}}{2 \gamma_{1}}
$$

In the case of coordinated policies, we can rewrite (A67) as:

$$
N^{I C}=\frac{\gamma_{0}}{2 \gamma_{1}}+\frac{\alpha N e(1-e)^{2}\left[\frac{(1-1 / \theta)}{(1-e) Y+\alpha N^{I C}(e / \theta+1-1 / \theta)}-\frac{(1-1 / \theta)}{(1-e) Y+\alpha N^{I C} e / \theta}\right]}{2 \gamma_{1}\left[\alpha N^{I C}+(x-1) Y\right]}
$$

Now, by for $\theta \rightarrow \infty$, (A71) becomes:

$$
N^{I C}=\frac{\gamma_{0}}{2 \gamma_{1}}+\frac{\alpha N e(1-e)^{2}\left[\frac{1}{(1-e) Y+\alpha N^{I C}}-\frac{1}{(1-e) Y}\right]}{2 \gamma_{1}\left[\alpha N^{I C}+(x-1) Y\right]}<\frac{\gamma_{0}}{2 \gamma_{1}}
$$

Comparing (A70) and (A72), it follows that $N^{I U}>N^{I C}$ when $\theta=\infty$.

Re. 3: In the third step, to show uniqueness of $\hat{\theta}$ we need, as described above, to prove that $\frac{\partial N^{I U}}{\partial \theta}>0$ and $\frac{\partial N^{I C}}{\partial \theta}<0$. The first requirement is proved by differentiating (A37) with respect to $\theta$ :

$$
\frac{\partial N^{I U}}{\partial \theta}=\frac{1}{2 \gamma_{1} \theta^{2}\left(N+N^{I U}\right)}
$$

implying that $\partial N^{I U} / \partial \theta>0$. Second, to show that $\partial N^{I C} / \partial \theta<0$, the first order condition of (A60) with respect to $N^{I C}$, in case of coordinated policies, can be written as:

$$
\gamma_{0}-2 \gamma_{1} N^{I C}+F\left(\theta, N^{I C}\right)=0
$$

where:

$$
F\left(\theta, N^{I C}\right)=\frac{\alpha N e(1-e)^{2}(\theta-1)\left[\frac{1}{\theta(1-e) Y+\alpha N^{I C}(e+\theta-1)}-\frac{1}{\theta(1-e) Y+\alpha N^{I C} e}\right]}{\alpha N^{I C}+(x-1) Y}<0
$$


Furthermore, the second-order condition of (A60) yields:

$$
-2 \gamma_{1}+F_{N^{I}}^{\prime}\left(\theta, N^{I C}\right)<0
$$

Now, from total differentiation of (A74) we get:

$$
\frac{\partial N^{I C}}{\partial \theta}=\frac{F_{\theta}^{\prime}\left(\theta, N^{I C}\right)}{2 \gamma_{1}-F_{N^{I}}^{\prime}\left(\theta, N^{I C}\right)}
$$

where the denominator is positive by the second-order condition of (A76). Furthermore, we can show that $F_{\theta}^{\prime}\left(\theta, N^{I C}\right)<0$ by differentiation of (A75) with respect to $\theta$ :

$$
\begin{aligned}
& F_{\theta}^{\prime}\left(\theta, N^{I}\right)=\frac{D}{\theta^{2}} {\left[\frac{1}{(1-e) Y+\alpha N^{I} e / \theta+\alpha N^{I}\left(1-\frac{1}{\theta}\right)}-\frac{1}{(1-e) Y+\alpha N^{I} e / \theta}\right] } \\
&-D\left(1-\frac{1}{\theta}\right) \alpha N^{I} / \theta^{2}\left(\frac{1}{(1-e) Y+\alpha N^{I} e / \theta+\alpha N^{I}\left(1-\frac{1}{\theta}\right)}\right)^{2} \\
&+D\left(1-\frac{1}{\theta}\right)\left(\alpha N^{I} e / \theta^{2}\right)\left[\begin{array}{c}
\left(\frac{1}{(1-e) Y+\alpha N^{I} e / \theta+\alpha N^{I}\left(1-\frac{1}{\theta}\right)}\right)^{2} \\
-\left(\frac{1}{(1-e) Y+\alpha N^{I} e / \theta}\right)^{2}
\end{array}\right]<0
\end{aligned}
$$

where $D=\frac{\alpha N e(1-e)^{2}}{\alpha N^{I}+(x-1) Y}$. Thus, $\partial N^{I C} / \partial \theta<0$, which concludes the proof concerning $N^{I}$

From the expressions for $t$ in (A36) and (A58), it follows that:

$$
\frac{\partial t}{\partial N^{I}}=\frac{\alpha N \theta(1-e)^{2}(1-\theta)}{\left[\theta\left(\alpha N^{I}+(x-1) Y\right)\right]^{2}}<0
$$

Combined with $N^{I U}<N^{I C}$ when $\theta<\hat{\theta}$, and vice versa when $\theta>\hat{\theta}$, this proves the part of Proposition 2 that concerns $t$.

Similarly, from the equations (A35) and (A57), it follows that:

$$
\frac{\partial b}{\partial N^{I}}=\frac{\alpha N \theta e(1-e)(1-\theta)}{\left[\theta\left(\alpha N^{I}+(x-1) Y\right)\right]^{2}}<0
$$

Combined with $N^{I U}<N^{I C}$ when $\theta<\hat{\theta}$, and vice versa when $\theta>\hat{\theta}$, this proves the part of Proposition 2 that concerns $b$.

The final part of Propositon 2 is proved by noticing that, since the expressions for optimal choices of $b$ and $t$ as functions of $N^{I}$ are identical in the two policy cases, the uncoordinated solution can always can be attained in the case of coordinated policies. 
However, since different solutions are chosen in the uncoordinated case (depending on $\theta \gtreqless \hat{\theta}), N^{I C}$ is revealed preferred to $N^{I U}$, and it therefore follows that $S W^{U}<S W^{C}$ in both cases. 


\section{References}

[1] Beetsma, R. H. and Uhlig (1999): "An Analysis of the Stability and Growth Pact", Economic Journal, 109, 546-571.

[2] Boeri, T. and H. Brücker (2005): "Why are Europeans so Tough on Migrants?", Economic Policy, 20, 629-703.

[3] Borjas, G.J. (1999): "Immigration and Welfare Magnets", Journal of Labor Economics, 17, 607-637.

[4] Borjas, G.J. (2003): "The Labor Demand Curve is Downward Sloping: Re-examining the Impact of Immigration on the Labor market", Quarterly Journal of Economics, $118,1335-1374$.

[5] Chari, V.V. and P.J. Kehoe (1990): "International Coordination of Fiscal Policy in Limiting Economies", Journal of Political Economy, 98, 617-36.

[6] Devereux, M.B. (1991): "The Terms of Trade and the International Coordination of Fiscal Policy", Economic Inquiry, 29, 720-36.

[7] Devereux, M.B. and A. Mansoorian (1992): "International Fiscal Policy Coordination and Economic Growth", International Economic Review, 33, 249-268.

[8] Dixon, H.D. and M. Santoni (1997): "Fiscal Policy Coordination with Demand Spillovers and Unionised Labour Markets", Economic Journal, 107, 403-417.

[9] Dustmann, C. and I. Preston (2004): "Racial and Economic Factors in Attitudes to Immigration", CReAM Discussion Paper No. 1/04.

[10] European Commission (2005): "Green Paper on an EU Approach to Managing Economic Migration", $\operatorname{COM}(2004) 811$ final.

[11] Hansen, J.D. (2003): "Immigration and Income Redistribution in Welfare States", European Journal of Political Economy, 19, 735-746. 
[12] Hatton, T.J. (2007): "Should we have a WTO for International Migration?", Economic Policy, 22, 339-383.

[13] Hillman, A.L. (2002): "Immigration and Intergenerational Transfers" in H. Siebert (Ed.) Economic Policies of Aging Societies. Springer, Berlin, pp. 213-226.

[14] Moses, J.W. and B. Letnes (2004): "The Economic Costs to International Labour Restrictions: Revisiting the Empirical Discussion", World Development, 32, 16091626.

[15] Wildasin, D.E. (1991): "Income Redistribution in a Common Labor Market", American Economic Review, 81, 757-774.

[16] Wildasin, D.E. (1994): "Income Redistribution and Migration", Canadian Journal of Economics, 27, 637-656.

[17] Zorlu, A. and J. Hartog (2005): "The Effects of Immigration on Wages in three European Countries", Journal of Population Economics, 18, 113-151. 